\title{
Characterization and flexural strength of iceberg and glacier ice
}

\author{
R. E. GAGNON \\ Institute for Marine Dynamics, National Research Council of Canada, St. John's, Newfoundland A1B 3T5, Canada \\ P. H. GAMMON \\ Consolidated Technologies Limited, 37 Stavanger Drive, St. John's, Nerefoundland A1A 5E8, Canada
}

\begin{abstract}
Flexural strength of iceberg and glacier ice was determined from four-point beam-bending experiments. A large quantity of glacial ice was collected from four icebergs and one glacier, and a detailed ice-characterization program was performed on samples from the five sources. Beam-bending experiments were conducted at four temperatures in the range $-1^{\circ}$ to $-16^{\circ} \mathrm{C}$ and at strain rates of $10^{-3}$ and $10^{-5} \mathrm{~s}^{-1}$. The flexural strength was found to increase with increasing strain rate (based on extreme fibre strain) and decreasing temperature. The data suggest that airbubble inclusions play an important role in determining the flexural strength of glacial ice and this can explain the significant differences in mean strength of the ice from the five sources. At a strain rate of $10^{-3} \mathrm{~s}^{-1}$ and temperature of $-11^{\circ} \mathrm{C}$, the flexural strength was found to increase as the number of bubbles per unit volume increased. Reduction of crack-initiating stresses at grain boundaries by "softening" of grains due to intragranular air-bubble inclusions is thought to be the mechanism.
\end{abstract}

\section{INTRODUCTION}

Icebergs, large floating pieces of glacier ice, pose a serious hazard to ships and offshore structures in the North Atlantic Ocean and other cold marine regions of the world. As many as 1600 icebergs have been recorded south of $48^{\circ} \mathrm{N}$ in a year. From Signal Hill, at the entrance to St. John's harbour (east coast of Newfoundland), one of the authors (R.E.G.) observed up to 60 icebergs at one time dotting the ocean in May 1991.

In 1981-82, Mobil Oil Corporation funded the first phase of a major research program on the physical and mechanical properties of iceberg ice. This effort was aimed at assessing the structural requirements for the development of offshore resources in the waters off the east coast of Canada. Prior to this, there was no information on iceberg-ice properties available in the literature. The first data on iceberg-ice mechanical properties, from two separate studies, were reported in 1983. One program involved uniaxial compression tests and indentation tests on ice from a single iceberg (Arockiasamy and others, 1983 ) and the other study involved uniaxial compression experiments on ice from five difference icebergs (Gammon and others, 1983). The Mobil-sponsored work described here involved the collection of large quantities of ice from an iceberg located off Labrador, and smaller amounts from three icebergs off Greenland and a Greenland glacier. Temperature profiles, to several meters depth, were obtained for the Labrador iceberg. Impact experiments, triaxial tests and beam-bending tests were performed on the ice in the laboratory.
This paper reports the results of the beam-bending component of the test program and provides an explanation for the observed differences in flexural strength between the ice from the five different sources.

\section{FIELD PROGRAM}

A $10 \mathrm{~d}$ field program to obtain ice for the experiments was carried out in May 1982 on a deteriorated iceberg surrounded by pack ice in Okak Bay, Labrador. The coordinates of the iceberg, lying $120 \mathrm{~km}$ north of Nain, Labrador, were $57^{\circ} 39.0^{\prime} \mathrm{N}, 61^{\circ} 50.0^{\prime} \mathrm{W}$.

The estimated mass of the Okak Bay iceberg was 0.6 Mtonne $\left(0.6 \times 10^{9} \mathrm{~kg}\right)$. The iceberg had a sail height of $60 \mathrm{~m}$ and was aground in $52 \mathrm{~m}$ of water. The iceberg had been on the site for at least a full year prior to May 1982.

Blocks of ice were quarried from the iceberg using chain saws. During the first $2 \mathrm{~d}$ of the field program, considerable difficulty was encountered in obtaining unbroken ice blocks. The slightest misalignment of sawcuts would result in a block splitting apart. However, with refinement of the quarrying technique, the chainsaw operators were eventually able to cut out between seven and ten blocks per day.

After each block had been quarried, it was immediately trimmed and boxed to be moved later to the landing site of the Twin Otter aircraft, for transport to a cold-storage facility in Goose Bay, Labrador. The storage-facility temperature was $-20^{\circ} \mathrm{C}$. 
A total of 42 blocks was collected by the end of the field program. Each block was approximately $74 \mathrm{~cm} \times$ $74 \mathrm{~cm} \times 31 \mathrm{~cm}$ in size, with a mass of $155 \mathrm{~kg}$.

The day after the field program, all the boxes were shipped by air to their final destination in St. John's, Newfoundland. Prior to loading in Goose Bay, the boxes were removed from the freezer facility to elevate the ice temperature overnight, thus reducing the risk of cracking during shipping and handling. At St. John's, boxes were stored in a commercial freezer warehouse at a temperature of $-22^{\circ} \mathrm{C}$.

In addition to the ice from the Labrador iceberg, Mobil conducted a field program to collect ice in Greenland in July 1982. Using the same methods as described above, a block of ice was obtained from a Greenland glacier and a block was cut from each of three different icebergs.

\section{ICE CHARACTERIZATION}

Bubble-size analysis was performed on the five types of ice studied in this program. Long and short dimensions were measured for all bubbles (some bubbles were elongated) within a suitable area of a thin plate of ice approximately $4 \mathrm{~mm}$ in thickness. The area was of sufficient size to obtain statistics on at least 28 bubbles. The analysis yielded average long and short bubble dimensions and also the maximum observed bubble diameters. Table 1 gives the results of the bubble-size analysis. This information, along with known values for the ice porosity, was used to ascertain the absolute bubble densities (number of bubbles per unit volume of ice) used in the analysis below. It is important to note that for all five ice types there were no significant accumulations of bubbles at grain boundaries. The bubbles were fairly evenly distributed throughout the ice, including the interiors of grains.

The percentage of the total volume of a sample of ice which is occupied by air bubbles is defined as the fractional porosity of the ice. Porosity is usually determined from measurements of density. The density of homogeneous ice (no inclusions) is known to be very nearly constant, i.e. independent of dissolved trace impurities, crystal-grain structure and thermal history. This zero-porosity limit for the density of ice is $916.9 \mathrm{~kg}$ $\mathrm{m}^{-3}$ at $0^{\circ} \mathrm{C}$. Using this value for homogeneous ice density along with volume and mass determinations of the ice samples by immersion in pure water at $0^{\circ} \mathrm{C}$, the fractional porosities representing the five ice types have been measured to yield the data in Table 2 .

Crack-density analysis (crack density was defined as cracks per unit length on a straight line) was performed on a slab of Labrador ice. The slab $(25 \mathrm{~cm} \times 25 \mathrm{~cm} \times$ $1 \mathrm{~cm}$ ) was suitably illuminated to highlight its cracks and the number was counted along each of two lines of equal length which formed a right-angle at the intersection of their midpoints. The mean crack density was obtained by taking the average of the two-line densities. The

Table 1. Ice-characterization data

\begin{tabular}{|c|c|c|c|c|c|c|c|c|c|}
\hline $\begin{array}{l}\text { Ice type and } \\
\text { orientation }\end{array}$ & $\begin{array}{c}\text { Mean grain } \\
\text { diameter }\end{array}$ & $\begin{array}{l}\text { Standard } \\
\text { deviation }\end{array}$ & $\begin{array}{c}\text { Maximum } \\
\text { observed grain } \\
\text { diameter }\end{array}$ & $\begin{array}{c}\text { Mean long and } \\
\text { short bubble } \\
\text { diameter }\end{array}$ & $\begin{array}{l}\text { Standard } \\
\text { deviation }\end{array}$ & $\begin{array}{l}\text { Maximum } \\
\text { observed bub- } \\
\text { ble diameter }\end{array}$ & $\begin{array}{l}\text { Bubble } \\
\text { density }\end{array}$ & $\begin{array}{c}\text { Preferred } \\
\text { c-axis } \\
\text { orientation }^{*}\end{array}$ & $\begin{array}{c}\text { Grain } \\
\text { elongation }\end{array}$ \\
\hline & $\mathrm{mm}$ & $\mathrm{mm}$ & $\mathrm{mm}$ & $\mathrm{mm}$ & $\mathrm{mm}$ & $\mathrm{mm}$ & $\# \mathrm{~mm}^{-3}$ & & \\
\hline G1 & 9.16 & 5.73 & 31.63 & 0.38 & 0.28 & 1.20 & 1.30 & Moderate & Slight \\
\hline G1P & 3.96 & 1.77 & 10.75 & 0.33 & & & & & \\
\hline G1PP & 12.95 & 5.17 & 25.64 & & & & & & \\
\hline G2 & 16.55 & 6.07 & 37.94 & 0.34 & 0.23 & 1.20 & 0.49 & Moderate & Slight \\
\hline G2P & 15.84 & 5.30 & 35.21 & 0.27 & & & & & \\
\hline G2PP & 24.44 & 6.06 & 35.32 & & & & & & \\
\hline G3 & 18.91 & 8.43 & 40.48 & 0.55 & 0.39 & 1.46 & 0.40 & Moderate & Slight \\
\hline G3P & 23.40 & 8.62 & 61.25 & 0.39 & & & & & \\
\hline G3PP & 23.30 & 10.38 & 57.55 & & & & & & \\
\hline G4 & 16.43 & 7.73 & 42.97 & 0.30 & 0.14 & 0.69 & 3.02 & Moderate & Moderate \\
\hline G4P & 17.92 & 9.59 & 49.52 & 0.23 & & & & & \\
\hline G4PP & 18.06 & 9.86 & 51.30 & & & & & & \\
\hline L04 & 9.69 & 4.53 & 22.83 & 0.32 & 0.21 & 1.09 & 2.66 & Strong & Moderate \\
\hline L04P & 8.71 & 3.26 & 20.92 & 0.27 & & & & & \\
\hline L04PP & 6.03 & 2.21 & 12.97 & & & & & & \\
\hline
\end{tabular}

\footnotetext{
* Moderate preferred $c$-axis orientation implies $20 \%$ of grains align simultaneously to extinction. Strong preferred $c$-axis orientation implies greater than $35 \%$ of grains align simultaneously to extinction.
} 
Table 2. Fractional porosity

\section{Sample type Number of measurements \\ Fractional porosity}

$\%$

$\begin{array}{lll}\text { G1 } & 10 & 3.0 \pm 0.35 \\ \text { G2 } & 10 & 0.7 \pm 0.20 \\ \text { G3 } & 10 & 2.0 \pm 0.26 \\ \text { G4 } & 10 & 2.8 \pm 0.23 \\ \text { L04 } & 10 & 3.5 \pm 0.38\end{array}$

analysis yielded $0.66 \mathrm{cracks} \mathrm{cm}^{-1}$ for one line and $0.58 \mathrm{cracks} \mathrm{cm}^{-1}$ for the other, which implied an average crack density of $0.63 \mathrm{cracks} \mathrm{cm}^{-1}$. Though no strong case for preferred crack orientation could be inferred from these numbers, it was nevertheless clear from visual inspection that two distinct populations were present, each consisting of cracks aligned roughly parallel to each other and at approximately right-angles to cracks of the other population.

Three mutally orthogonal thin sections were taken from each of the five types of ice. In Table 1, the three different orientations are distinguished by the absence or presence of a single or double letter $\mathrm{P}$ (for perpendicular) which appears after the ice-source ID number. Photographs in crossed polarized light were analyzed to yield grain-diameter statistics. Texture and fabric were inferred from inspection of thin sections. Preferred $c$-axis orientation was indicated when a significant fraction of grains aligned simultaneously to extinction.

Grain-size analysis was patterned after methods used in determining sieve-diameter statistics from thin sections of sandstones and conglomerates (Adams, 1977). A detailed description of the thin-section analysis and method of translating thin-section statistics into threedimensional grain population is given in the Appendix.

In the sub-sections which follow, mean and standard deviation for crystal-grain diameter are sieve mean and sieve standard deviation, respectively. Maximum measured grain diameter is the grain-section maximum. All bubble-diameter statistics are taken directly from the thin sections without including correction for sectioning effect.

Unless otherwise specified, the diameter of the thin sections used in the analysis below is $75 \mathrm{~mm}$. In the ice source IDs below, the letters G and L represent Greenland and Labrador, respectively.

\section{Source G1}

Crystal grains were generally irregular in shape and ranged in size from small to moderate. Some were slightly interlocking. The smaller grains were usually rounded, while the large ones were more angular. Fabric demonstrated a fairly strong degree of preferred $c$-axis orientation. Texture showed a small amount of grain elongation and alignment. This ice was fairly complex as is indicated by the degree of texture variation between the three different thin sections.

Statistical grain-size analysis yielded the following results for the three orientations. For G1, G1P and G1PP, the numbers of grains measured were 85,94 and 82 , respectively. The mean sieve-grain diameters and standard deviations in sieve-grain diameters were 9.12 \pm 5.73 , $3.96 \pm 1.77$ and $12.95 \pm 5.17 \mathrm{~mm}$, respectively. The maximum observed grain diameters on the thin sections were $31.63,10.75$ and $25.64 \mathrm{~mm}$, respectively.

Measurements from 36 bubbles indicated a mean bubble diameter (in the direction of elongation) of $0.38 \mathrm{~mm}$ with a standard deviation of $0.28 \mathrm{~mm}$. The maximum observed bubble diameter was $1.20 \mathrm{~mm}$. The mean bubble diameter (normal to the direction of elongation) was $0.33 \mathrm{~mm}$.

\section{Source G2}

Grains were generally irregular in shape and ranged from intermediate to large in size. Some grains were angular and polygonal, while others were more rounded. Some grain interlocking was also present. Fabric demonstrated a fairly strong preferred $c$-axis orientation. Texture was essentially isotropic.

Grain-size analysis yielded the following results. For $\mathrm{G} 2$, G2P and G2PP, the numbers of measured grains were 66, 78 and 48, respectively. Thin sections with diameters larger than $75 \mathrm{~mm}$ were used for the analysis, because the grains were large. The mean sieve-grain diameters and the standard deviations in sieve-grain diameters were $16.55 \pm 6.07,15.84 \pm 5.30$ and $24.44 \pm 6.06 \mathrm{~mm}$, respectively. The maximum grain diameters observed on the thin sections were $37.94,35.21$ and $35.32 \mathrm{~mm}$, respectively.

Measurements from 29 bubbles indicated a mean bubble diameter (in the direction of elongation) of $0.34 \mathrm{~mm}$ with a standard deviation of $0.23 \mathrm{~mm}$. The maximum observed bubble diameter (normal to the direction of elongation) was $0.27 \mathrm{~mm}$.

\section{Source G3}

Grain-size ranged from moderate to large. Most grains were irregular in shape, some rounded and others angular. A moderate amount of grain-interlocking was evident. Some recrystallization after crack formation was indicated by cracks which formed grain boundaries. A fairly strong degree of preferred $c$-axis orientation was also present. Texture revealed a slight amount of grain elongation and alignment which resulted for the most part from the distribution and orientation of cracks.

Thin sections with diameters larger than $75 \mathrm{~mm}$ were used for the analysis because the grains were large. The following results for the three orientations were obtained. For G3, G3P and G3PP, the numbers of measured grains were 60,66 and 65 , respectively. The mean sievediameters and standard deviations in sieve-grain diameters were $18.91 \pm 8.43,23.40 \pm 8.62$ and $23.30 \pm$ $10.38 \mathrm{~mm}$, respectively. The maximum observed grain diameters on the thin sections were 40.48, 61.25 and $57.55 \mathrm{~mm}$, respectively.

Measurements from 28 bubbles indicated a mean 
bubble diameter (in the direction of elongation) of $0.55 \mathrm{~mm}$ with a standard deviation of $0.39 \mathrm{~mm}$. The maximum observed bubble diameter (length) was $1.46 \mathrm{~mm}$. The mean bubble diameter (normal to the direction of elongation) was $0.39 \mathrm{~mm}$.

\section{Source G4}

This ice was complex in texture, as was indicated by the degree of variation between the three orientations. Grains ranged in size from small to very large and the majority were irregular in shape. Both angular and rounded grains were present and some degree of interlocking was evident. Also, a moderate amount of recrystallization after crack formation was present. Fabric indicated a fairly strong degree of preferred $c$-axis orientation. A certain amount of grain elongation and alignment was also evident.

Because some grains were large, it was necessary to use thin sections with a diameter greater than $75 \mathrm{~mm}$ for the statistical analysis. The following results for the three orientations were obtained. For G4, G4P and G4PP, the numbers of measured grains were 85, 63 and 94, respectively. The mean sieve-grain diameters and standard deviations in sieve-grain diameters were $16.43 \pm 7.73$, $17.92 \pm 9.59$ and $18.06 \pm 9.86 \mathrm{~mm}$, respectively. The maximum grain diameters observed on the thin sections were $42.97,49.52$ and $51.30 \mathrm{~mm}$, respectively.

Measurements from 29 bubbles indicated a mean bubble diameter (in the direction of elongation) of $0.30 \mathrm{~mm}$ with a standard deviation of $0.14 \mathrm{~mm}$. The maximum observed bubble diameter (length) was $0.69 \mathrm{~mm}$. The mean bubble diameter (normal to the direction of elongation) was $0.23 \mathrm{~mm}$.

\section{Labrador block No. 4}

This ice appeared to have two distinct grain populations, one which consisted of small-size grains and the other which was composed of moderate-size grains. Some appeared to be rounded but most were angular. In general, grains appeared irregular in shape. Fabric indicated a strong preferred $c$-axis orientation. A slight amount of grain alignment was evident in the texture.

Statistical grain-size analysis yielded the following results. For L04, L04P and L04PP, the numbers of measured grains were 76,57 and 70 , respectively. The mean sieve-grain diameters and standard deviations in sieve-grain diameters were $9.69 \pm 4.53,8.71 \pm 3.26$ and $6.03 \pm 2.21 \mathrm{~mm}$, respectively. The maximum grain diameters observed on the thin sections were 22.83, 20.92 and $12.97 \mathrm{~mm}$, respectively.

Measurements from 30 bubbles indicated a mean bubble diameter (in the direction of elongation) of $0.32 \mathrm{~mm}$ with a standard deviation of $0.21 \mathrm{~mm}$. The maximum observed bubble diameter (length) was $1.09 \mathrm{~mm}$. The mean bubble diameter (normal to the direction of elongation) was $0.27 \mathrm{~mm}$.

\section{SPECIMEN PREPARATION}

Beams were cut from Labrador and Greenland ice by means of a thermal saw consisting of two parallel mounted lengths of $3.2 \mathrm{~mm}$ copper tubing, separated by $12.7 \mathrm{~cm}$, through which warm fluid was circulated. Slabs, $12.7 \mathrm{~cm}$ in thickness, were cut from the ice blocks and then beams were obtained by using the saw at rightangles to the slab sides. The ice temperature just prior to the cutting of the beams was approximately $-5^{\circ} \mathrm{C}$. Beam surfaces were given a uniform finish by quick application to a warm metallic surface which melted any irregularities. The beams were then placed in storage at the temperature at which they were to be tested.

\section{APPARATUS}

A loading frame and hydraulic supply system were built specifically for the test program. The load frame was constructed from Al I beams. The capacity of the frame for loads applied at the center of the cross-beams was $178 \mathrm{kN}$. A hydraulic ram with a capacity of $445 \mathrm{kN}$ was incorporated into the frame at the top cross-beams. The frame stood $2 \mathrm{~m}$ high with separations of $102 \mathrm{~cm}$ and $89 \mathrm{~cm}$ between side columns and upper and lower crossbeams, respectively.

Hydraulic fluid at a fixed pressure of $12.8 \mathrm{MPa}$ was used to power the loading system. Flow rate was adjusted and set utilizing a fluid throttle valve situated between the hydraulic supply and the load-frame ram. The load applied to the ice during a test was determined from the output of a pressure transducer installed in the hydraulic line between the throttle valve and the load-frame ram. This output was fed directly into the data-acquisition system.

The upper loader consisted of three pillow-block bearings $(22.2 \mathrm{kN}$ capacity) housed in stainless-steel jackets which were rigidly fixed to a strong aluminum chassis, one on top and two on the bottom (Fig. 1). During a test, the top bearing made contact with the ram head and the other two were in contact with the ice specimen. The ability of the bearings to tilt and roll enabled the loader to accommodate some degree of offcenter loading and it also diminished load-point stress concentration at the upper surface of the beams, where compressional strain occurred during testing. The loader stood $41 \mathrm{~cm}$ in height and had a mass of $34 \mathrm{~kg}$.

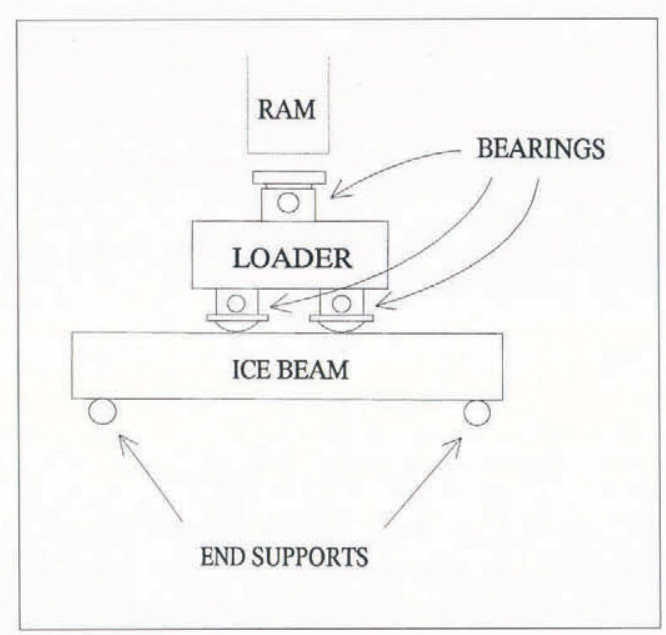

Fig. 1. Beam-bending test configuration. 
Ram speed was determined by using a device which essentially consisted of a ten-turn potentiometer configured to the ram head and the load frame, so that any ram motion would result in rotation of the potentiometer. The output from the potentiometer was electronically differentiated so that a given ram speed $\left(\mathrm{mm} \mathrm{s}^{-1}\right)$ could be correlated with a change in resistance per unit time $\left(\mathrm{ohm} \mathrm{s}^{-1}\right)$, which would be monitored by a digital display.

\section{TEST PROGEDURE}

Prior to each test, accurate determinations of dimensions at both ends of the beam were obtained. If slight variations were present between opposite ends, then the average value was used in subsequent data analysis. After a beam had been measured, it was placed on the lower two support points. The upper loader was then laid on to the supported specimen. Care was taken to insure that the loader was centered relative to the lower supports and vertical relative to the load frame and ram. An initial gap of approximately $1.5 \mathrm{~cm}$ was deliberately left between the loading ram and the loader. This gave rise to a finite time interval between the onset of ram motion and the commencement of specimen loading. During this interval, the ram speed was adjusted by controlling the throttle until the desired output appeared on the speedometer digital display. The data-acquisition system was switched on when there was typically $1 \mathrm{~mm}$ of separation left between the loader and the moving ram. Load immediately began to accumulate after ram contact until the beam eventually fractured. The fluid throttle was shut off shortly after the beam failure. The test concluded with photographic documentation of the failure mode.

Forty-two of the beams were tested with the lower supports separated by $0.727 \mathrm{~m}$ and with the upper load points separated by $0.243 \mathrm{~m}$. The remaining four beams, which were taken from a Greenland ice block damaged with chain-saw cuts, were short enough to necessitate adjusting the lower supports to a $0.538 \mathrm{~m}$ separation and the upper load points to a $0.182 \mathrm{~m}$ separation.

A total of 46 beam-bending tests was conducted during the course of the program, 30 tests on Labrador specimens and 16 tests on Greenland samples. The beambending test parameters are given in Table 3 . In addition, a statistical summary of the beam-bending tests is given in Table 4. The ordering of the tests is first by decreasing strain rate, then for tests in the same strain-rate series, by decreasing temperature. Strain rate was defined in terms of the strain at the extreme fibre along the bottom of the beam. From beam-bending theory for four-point loading, this is given by

$$
\text { Strain rate }=h s /\left(l c-\frac{4}{3} c^{2}\right)
$$

where $h$ is the beam height, $s$ is the ram speed, $l$ is the separation of the outer support points and $c$ is the distance between an outer support point and an adjacent loading point.
Table 4. Beam-bending test statistics

\begin{tabular}{clrrrr}
\hline $\begin{array}{c}\text { Data } \\
\text { set }\end{array}$ & Ice type & Flexural strength & $\begin{array}{c}\text { Mean } \\
\text { strain rate }\end{array}$ & $\begin{array}{c}\text { Specimen } \\
\text { temper } \\
\text { ature }\end{array}$ \\
& & & & & \\
& & Mean & Std. dev. & & \\
& & & & $\times 10^{-6} \mathrm{~s}^{-1}$ & ${ }^{\circ} \mathrm{C}$ \\
\hline & & & & & \\
\hline & & & & & \\
1 & Labrador & 0.95 & 0.25 & 930.0 & -1 \\
2 & Labrador & 1.25 & 0.28 & 900.0 & -6 \\
3 & Labrador & 1.43 & 0.15 & 980.4 & -11 \\
4 & Labrador & 1.52 & 0.08 & 975.6 & -16 \\
5 & Labrador & 1.13 & 0.19 & 9.2 & -11 \\
6 & Greenland 1 & 1.27 & 0.15 & 810.0 & -11 \\
7 & Greenland 2 & 1.13 & 0.16 & 1770.0 & -11 \\
8 & Greenland 3 & 1.14 & 0.11 & 939.6 & -11 \\
9 & Greenland 4 & 1.43 & 0.29 & 903.6 & -11 \\
& & & & & \\
\hline
\end{tabular}

\section{RESULTS AND DISCUSSION}

Test No. 3.3 represents a typical beam-bending experiment. The primary vertical crack associated with failure of the specimen occurred in the central region between the two upper load points. This crack initiated at the bottom of the beam where tensile stress was maximal. On closer inspection, two other cracks forming a Y shape with the primary crack were evident in the upper part of the beam. These cracks resulted from the longitudinal compressional stress in the upper part of the beam between the inner loading points. This stress led to the failure of the ice in shear along planes angled approximately $45^{\circ}$ from the compressional stress axis. Y-shaped cracks were present in several specimens. Other beams exhibited single or multiple cracks, some of which occurred beneath the upper load points.

Figure 2 shows flexural stress versus time for test No.

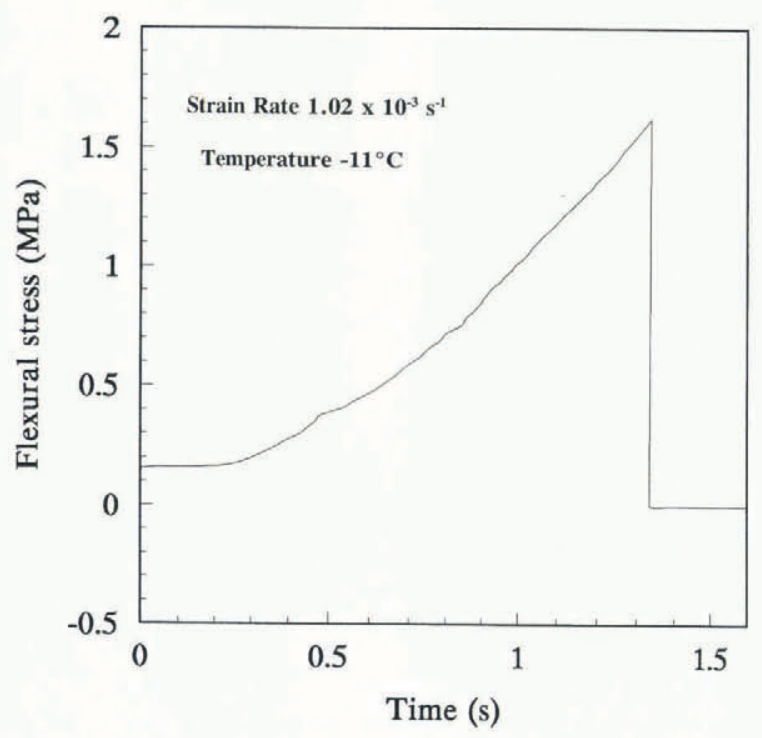

Fig. 2. Plot of flexural stress versus time from beambending test No. 3.3 performed on Labrador ice at a temperature of $-11^{\circ} \mathrm{C}$ and a strain rate of $1.02 \times 10^{-3} \mathrm{~s}^{-1}$. 
Text No. Flexural strength Strain rate $\mathrm{MPa} \times 10^{-6} \mathrm{~s}$

0.79

0.95

1.41

0.84

1.00

0.73

1.6

2.1

2.2

2.3

2.4

2.5

2.6

3.1

3.2

3.3

3.4

3.5

3.6

4.1

4.2

4.3

4.4

4.5

4.6

5.1

5.2

5.3

5.4

5.5

5.6

6.1

6.2

6.3

6.4

7.1

7.2

7.3

7.4

8.1

8.2

8.3

8.4

9.1

9.2

9.3

9.4
1.00

0.83

1.31

1.43

1.58

1.36

1.35

1.50

1.62

1.25

1.30

1.58

1.62

1.48

1.60

1.52

1.46

1.43

1.14

1.49

1.11

1.10

0.99

0.97

1.30

1.34

1.39

1.05

0.90

1.26

1.20

1.16

0.97

1.19

1.21

1.18

1.71

1.19

1.63

1.17

\section{4}

996

792

984

996

948

996

1008

888

1020

672

816

1140

1044

1020

1020

948

708

1008

924

900

996

996

1032

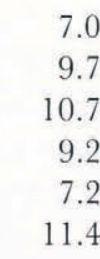

684

684

948

924

1800

1680

1800

1800

1116

1020

828

792

1104

828

828

852
Time to failure Specimen temperature

Ice type

${ }^{\circ} \mathrm{C}$

$-1$

Labrador

Labrador

Labrador

Labrador

Labrador

Labrador

Labrador

Labrador

Labrador

Labrador

Labrador

Labrador

Labrador

Labrador

Labrador

Labrador

Labrador

Labrador

Labrador

Labrador

Labrador

Labrador

Labrador

Labrador

Labrador

Labrador

Labrador

Labrador

Labrador

Labrador

Greenland 1

Greenland 1

Greenland 1

Greenland 1

Greenland 2

Greenland 2

Greenland 2

Greenland 2

Greenland 3

Greenland 3

Greenland 3

Greenland 3

Greenland 4

Greenland 4

Greenland 4

Greenland 4 
3.3. The stress level starts at a finite value, corresponding to the stress resulting from the weight of the loader itself. When the ram made contact with the loader, stress accumulated rapidly in a fairly linear fashion until failure was realized, after which the measured stress immediately returned to zero. The maximum flexural stress obtained just prior to failure is defined as the flexural strength of the beam. This test was conducted at a temperature of $-11^{\circ} \mathrm{C}$ and a strain rate of $1.02 \times 10^{-3} \mathrm{~s}^{-1}$. The time to failure once load began to accumulate was approximately 1s (Table 3).

The standard expression derived from beam-bending theory for four-point loading was used to determine flexural strengths for all the beams tested in this program. This is given by

$$
\text { Flexural strength }=3 p c /\left(b h^{2}\right)
$$

where $p$ is the peak applied load, $c$ is the separation between upper load points and end supports, $b$ is the beam thickness and $h$ is the beam height.

The charts and tabulated data indicate that the Labrador ice tested at a strain rate of $10^{-3} \mathrm{~s}^{-1}$ behaved in a consistent fashion with the flexural strength, increasing as temperature declined. Over the temperature range $-1^{\circ}$ to $-16^{\circ} \mathrm{C}$, the ice experienced a $60 \%$ increase in flexural strength (Fig. 3). This effect was most pronounced at the warmer temperatures. It is noteworthy that the degree of scatter in the data appeared to decrease at the lower temperatures. This was probably due to uncertainty in the cold-room temperature $\left( \pm 1^{\circ} \mathrm{C}\right)$ which would have had a more pronounced effect on the scatter at the higher temperatures where the slope of the fitted curve in Figure 3 is greater. Strain rate also influenced flexural strength.

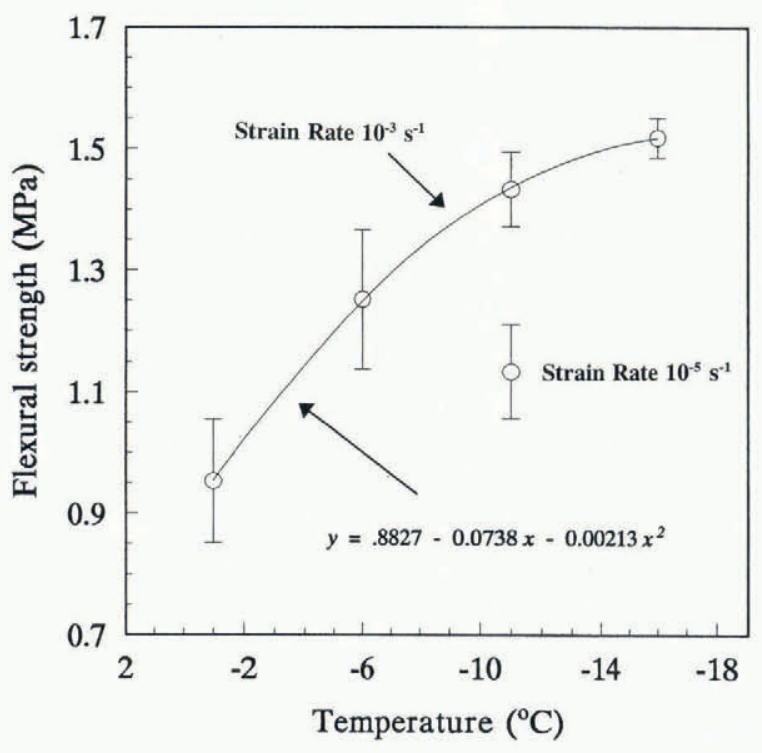

Fig. 3. Plot of flexural strength versus temperature for beam-bending tests on Labrador ice at a strain rate of $10^{-3} \mathrm{~s}^{-1}$. One point is also included for a set of tests performed at a strain rate of $10^{-5} \mathrm{~s}^{-1}$. Each point represents the mean strength for six tests and the corresponding error bar represents the standard error in the mean. Standard error is equal to standard deviation divided by the square root of the sample size.
The Labrador ice tested at $-11{ }^{\circ} \mathrm{C}$ and a strain rate of $10^{-3} \mathrm{~s}^{-1}$ was $26 \%$ stronger than the same ice tested at the lower strain rate of $10^{-5} \mathrm{~s}^{-1}$.

The Greenland ice, all of which was tested at a temperature of $-11^{\circ} \mathrm{C}$ and a strain rate of $10^{-3} \mathrm{~s}^{-1}$, exhibited marked differences in flexural strength (Fig. 4). Ice from source G4 was approximately $26 \%$ stronger than ice from sources G2 and G3. G1 ice was intermediate. All the mean strength values for Greenland ice were lower than the corresponding strength values for Labrador ice, although ice from source G4 approximately matched the Labrador-ice strength. The two highest individual flexural strengths recorded in the beambending program were for G4 specimens tested at $-11^{\circ} \mathrm{C}$. The flexural strengths of these two specimens exceeded the strengths of all Labrador specimens, including those tested at $-16^{\circ} \mathrm{C}$.

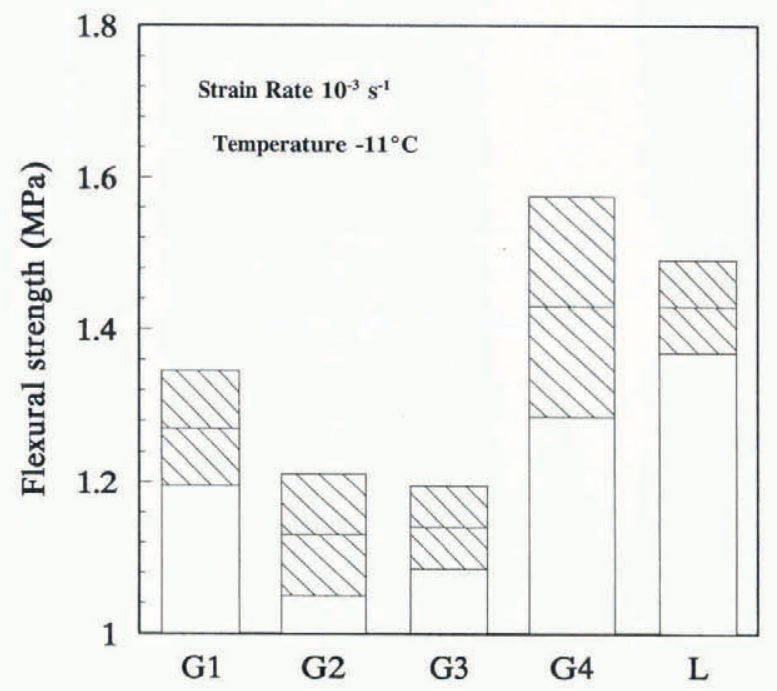

Fig. 4. Chart of flexural strength of Greenland and Labrador ice tested at a temperature of $-11^{\circ} \mathrm{C}$ and a strain rate of $10^{-3} \mathrm{~s}^{-1}$. On each vertical bar, the line through the middle of the hatched region represents the mean value of a set of strength data and the corresponding hatched region represents the standard error in the mean.

Variations in porosity, grain-size and shape, crack density and orientation, and preferred crystallographic $c$ axis orientation probably all play some role in determining the flexural strength of ice. However, no unambiguous correlations of flexural strength with these parameters were identifiable from the data. Analysis of the bubble population, on the other hand, demonstrated that the dominant factor differentiating the flexural strengths of the five ice types studied here is the bubble density, i.e. the number of bubbles per unit volume. The bubble density was determined from the expression

$$
\text { Bubble density }\left(\# \mathrm{~mm}^{-3}\right)=\nu \times 1 \mathrm{~mm}^{3} / V_{\text {bubble }}
$$

where $\nu$ is the fractional porosity of the ice and $V_{\text {bubble }}$ is the mean bubble volume of the ice, given by

$$
V_{\text {bubble }}=\frac{4}{3} \pi(S / 2)^{3}+(L-S) \pi(S / 2)^{2}
$$


where $L$ and $S$ are the mean long and mean short diameters of the bubbles.

Figure 5 shows the flexural strength versus bubble density for the ice from the five different sources at $-11^{\circ} \mathrm{C}$ and strain rate of $10^{-3} \mathrm{~s}^{-1}$. The flexural strength and bubble density are distinctly related. The flexural strength increases by approximately $27 \%$ over the range of bubble density $0.5-3 \mathrm{~mm}^{-3}$.

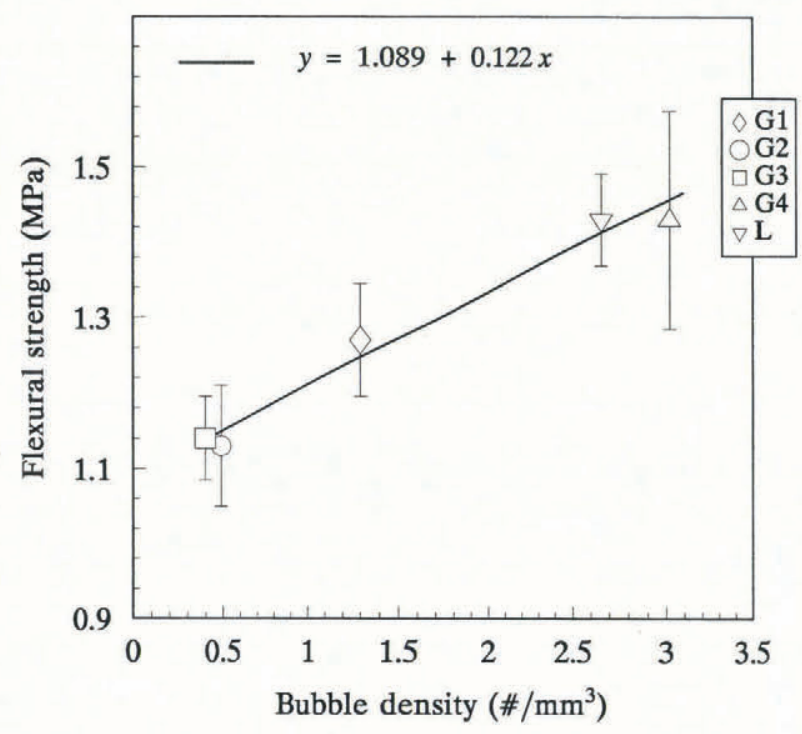

Fig. 5. Flexural strength versus bubble density for ice from the five sources tested at a temperature of $-11^{\circ} \mathrm{C}$ and $a$ strain rate of $10^{3} s^{-1}$. Each point represents the mean strength of four tests, except the Labrador one which represents six tests, and the corresponding error bar represents the standard error in the mean.

The primary crack in a beam-bending experiment initiates at a weak point, usually at a grain boundary. In glacial ice, grains may be "softened" by the presence of internal air-bubble voids, that is, able to accommodate more strain for a given stress than grains without bubbles. This would reduce the intergranular stress concentrations that lead to crack initiation at grain boundaries. Hence, the more bubbles in the ice, up to a certain degree at least, the greater the flexural strength. For sea ice, on the other hand, the strength decreases as the brine volume or total porosity (brine and air) (Timco and O'Brien, 1994) increases. The different behaviour is probably caused by the fact that voids and brine channels in sea ice are always located at grain or sub-grain boundaries. This is a consequence of the radically different formation histories of the two ice types. The more voids present at the grain boundaries, the weaker the ice becomes.

From the above considerations, it may be expected that ice from deep within glaciers and ice shelves would have a higher flexural strength than ice from shallower depths, since more recrystallization and grain-boundary migration would have occurred as a result of higher stresses and longer exposure to the stresses. This would tend to leave air bubbles inside grains rather than at the grain boundaries, where they would have initially been in the early stages of ice formation from snow. The uniaxial compressive-strength data from ice samples taken from a core through the entire thickness of Hobson's Choice Ice Island (Poplin and Ralston, 1992) supports this conclusion. Ice from the bottom region of the core tested at the same temperature and strain rate as ice from the top region was stronger. The authors could not account for this in terms of temperature, crystal structure or density of the ice. However, information about the physical characteristics and number of bubbles and their locations, would be required to establish conclusively a relationship between bubbles and strength for the Hobson's Choice Ice Island ice.

\section{SUMMARY AND CONCLUSIONS}

A comprehensive series of four-point beam-bending tests has been performed at various temperatures and strain rates on ice from four icebergs and one glacier. Detailed grain-size and air-bubble statistics were obtained for the five ice types. Qualitative information about fabric and texture was also obtained. The flexural strength was found to increase with increasing strain rate and decreasing temperature. Mean values of the flexural strength of ice from the five different sources showed considerable variation. The ability of the bearings in the loading device to accommodate some degree of rolling and tilting contributed to the overall quality of the data by minimizing cracking under the loading points.

The data suggest that intragranular air bubbles play an important role in determining the unconfined flexural strength of glacial ice and that this accounts for the observed differences in flexural strength of the ice from the five sources.

Other types of strength tests on ice, combined with airbubble data, would yield further details on the role of airbubble inclusions.

\section{AGKNOWLEDGEMENTS}

The authors are grateful to many individuals who worked on the field and laboratory aspects of this research. In particular, we thank G. Dinn, presently at Consolidated Technologies Ltd, who served as technical manager of the Labrador ice-collection program, and Dr D. Nevel and J. Benoit, who co-ordinated the work for Mobil Oil Canada, Ltd and assisted in the field work. Finally, we should like to thank Mobil Oil Canada, Ltd for the use of the data, and Hibernia Management and Development Company Ltd for assistance in providing the data.

\section{REFERENGES}

Adams, J. 1977. Sieve size statistics from grain measurement. f. Geol. 85, $209-227$.

Arockiasamy, M., H. El-Tahan, A. S. J. Swamidas, W. Russell and D. V. Reddy. 1983. Semi-submersible response to bergy-bit impact. Proceedings of the RINA Symposium on Semi-Submersibles: The New Generations, London, March 17-18, 1983. Paper No. 14. London, Royal Institute of Naval Architects.

Gammon, P.H., R.E. Gagnon, W. Bobby and W.E. Russell. 1983 Physical and mechanical properties of icebergs. In Fifteenth Annual Offshore Technology Conference, Houston, Texas, 1983. Proceedings. Vol. 1. 
Dallas, TX, Offshore Technology Conference, 143-150.

Poplin, J.P. and T.D. Ralston. 1992. Physical and mechanical properties of Hobson's Choice Ice Island cores. Cold Reg. Sci. Technol., 20, 207-223.

Timco, G. W. and S. O'Brien. 1994. Flexural strength equation for sea ice. Cold Reg. Sci. Technol., 22(3), 285-298.

\section{APPENDIX}

\section{GRAIN-SIZE ANALYSIS}

The analysis was complicated by two factors. First, the grain shapes in iceberg ice were much more irregular than those in common geological samples. Secondly, the grain diameters were often a significant fraction of the thinsection diameters.

Grain-diameter analysis can be broken down into three components. These include grain-sample selection, grain-diameter measurement and, finally, translation of thin-section statistics into statistics of the real threedimensional grain population. Grain selection should yield an unbiased statistical sample and is usually carried out by choosing grains lying under points in a grid overlying a thin-section photograph. The probability of selecting a grain is therefore proportional to its area (hence volume). The statistics then take the form of fractional volume occupied by grains in a given diameter category.

In the present instance, grains were selected by drawing a circle (diameter less than $75 \mathrm{~mm}$ ) on a thinsection photograph and selecting all grains, any part of which lay within the circle. Where possible, the circle was chosen large enough to include at least 50 grains and small enough to exclude any grains extending off the thinsection photograph. The point-selection criterion could not be used, since the resultant grain sample was generally too small.

The finite-area-selection method yielded a grainselection probability that differed from that of the point-selection criterion by a factor related to grain area. All data were thus weighted by an area factor (product of internal and external grain diameters) for purposes of calculating statistical moments.

Grain-diameter measurements consisted of an external diameter (diameter of smallest circle completely including the grain) and an internal diameter (diameter of largest circle completely included within the grain) for each grain. The first moment of the area-weighted distribution of external diameters was taken to be the mean diameter of the grain sections. The second moment of the areaweighted distribution of external diameters was used in calculating the standard deviation in the grain-section diameters.

Extrapolation of grain-section statistics to statistics of actual three-dimensional grains requires both an appropriate definition of three-dimensional grain diameter and an implicit assumption regarding grain shape. No rigorous method exists for making such an extrapolation. A comprehensive treatment of the problem is found in the paper by Adams (1977).

Following Adams, the three-dimensional grain statistics were calculated assuming an ellipsoidal model for grain shape and taking the sieve diameter to be a representative measure of grain-size. Accordingly, the mean sieve diameters for the various ice samples were determined from the mean external diameters for the grain sections via the equations of Adams. Similarly, the standard deviation in sieve-grain diameter was determined from the grain-section standard deviation, using an empirical relation derived by Adams. 